\title{
Awareness and willingness among the residents in Johor Bahru City Council and Johor Bahru Tengah Municipal Council of Iskandar Malaysia-Im (Wpi@Sjer) towards recycling
}

\author{
Nora Farina Mohd Halim ${ }^{1, *}$, Nur Zaidani Wati Mohd Darwis ${ }^{1}$, and Juliana Martin ${ }^{1}$ \\ ${ }^{1}$ Universiti Teknologi Mara (UiTM) Cawangan Johor, Kampus Pasir Gudang, Malaysia
}

\begin{abstract}
Solid waste is increasingly becoming an important urban challenge as a result from population growth and also the development of economy and culture which has improved the standard of living and the lifestyle of the people. If left unchecked, solid waste could lead to severe environmental degradation. In order to reduce the environmental impact of waste disposal, recycling has been introduced. About twenty percent of our solid waste can be recyclable, rather than disposing it through landfills or incinerators. Residential area is the best place to practice recycling because most of the waste is generated there every day. This research focus on the awareness level and the recycling knowledge among the residents in Johor Bahru City council and Johor Bahru Tengah Municipal Council of Iskandar Malaysia. A total of 500 residents were surveyed and the questionnaires were focused on the waste management and also the recycling knowledge. The results discovered that more than $50 \%$ of the residents' state that they practicing recycle and they also aware of the environmental and economic benefits from recycling. As a conclusion, the residents are prepared for recycling if the recycling amenities are available and easy to reach by them.
\end{abstract}

\section{Introduction}

In line with the vision 2020, the development of economic and urban transformation is emerging tremendously. The population in Malaysia has extended up to 30 million people in year 2016 according to the Department of Statistics Malaysia. The growing of the population contributes to the increase of solid waste production in Malaysia.

Besides that, the changes of living standard and a variety of daily activities among Malaysian will also lead to this excessive solid waste production [1]. Even though "Recycling" has been accepted worldwide as a method of waste disposal, Malaysia's domestic recycling rate is still low at about five percent [2]. Iskandar Malaysia has presented a severe waste generation growth from time to time.

Waste reduction and recycling are no longer a preference but a needed step to ensure a healthy life style and at also to protect our surrounding. Conferring to [3], Malaysia is one of the Asian countries that produced the most municipal solid waste

Recycling is the method of changing waste materials into reusable objects to avoid waste of possibly useful materials, lessen the intake of fresh raw materials, energy usage, air pollution and water pollution .Recycling is a key element of modern waste reduction and is the third element of the "Reduce, Reuse and Recycle" waste hierarchy [4].

Recycling is a process of reusing items that would be rejected as waste. There are few types of recycling include upcycling, which involves adding value to an element for reuse, and downcycling, which involves breaking down an element or material into its component to reuse anything that can be reclaimed.

Precycling is a different approach which involves avoiding the acquisition of excessive items that would have eventually have to be recycled or dealt with as waste.

\footnotetext{
* Corresponding author: norafarina@johor.uitm.edu.my ${ }^{1}$, nurzaidaniwati@johor.uitm.edu.my ${ }^{2}$, julianamartin@johor.uitm.edu.my ${ }^{3}$
} 


\section{Study area}

The leading southern development corridor in Johor is Iskandar Malaysia (IM) which previously known as South Johor Economic Region (SJER). On 8 November 2006 Iskandar Malaysia was established. The development is managed by Iskandar Regional Development Authority (IRDA) and was named after the late Sultan of Johor, Almarhum Sultan Iskandar ibni Almarhum Sultan Ismail [5]. Figure 1 and Figure 2 show the whereabout and geographical coverage of Iskandar Malaysia.

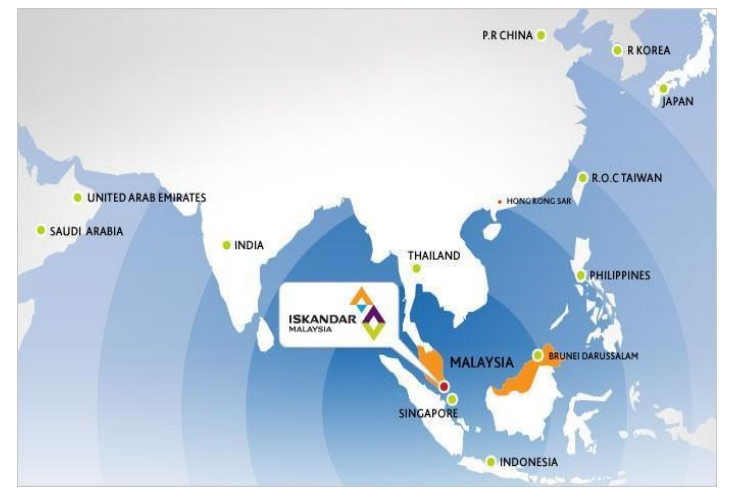

Figure 1: Location of Iskandar Malaysia

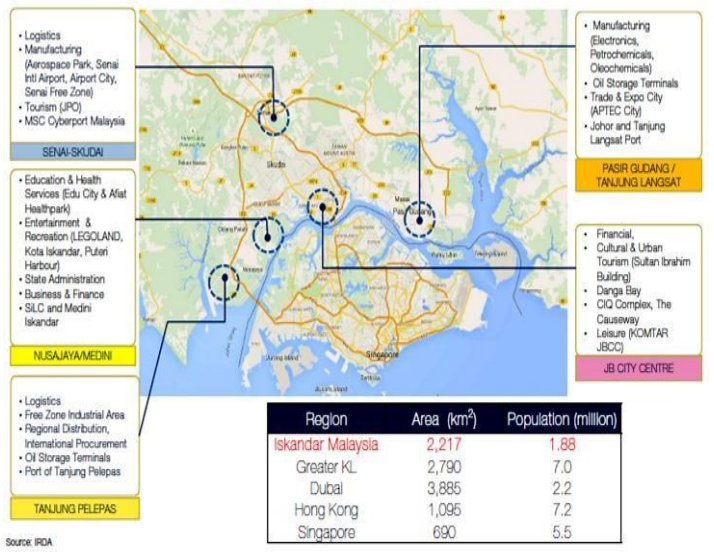

Figure 2: Geographical Coverage of Iskandar Malaysia

The total area of the development region of IM is 2217 square kilometres which cover the city of Johor Bahru, Pontian, Senai, Pasir Gudang and the new administrative investment in Iskandar Puteri. The district of Johor Bahru is included in its whole, as well as the parts of the district of Pontian. Five local government authorities have the jurisdiction over the covered area, including Majlis Bandaraya Johor Bahru, Majlis Perbandaran Johor Bahru Tengah, Majlis Perbandaran Pasir Gudang, Majlis Perbandaran Kulai,and Majlis Daerah Pontian . In this research we just focus on the awareness level and the recycling knowledge of the two local jurisdiction of the local authority in Iskandar Malaysia which is Majlis Bandaraya Johor Bahru and Majlis Perbandaran Johor Bahru Tengah

\section{Methodology}

\subsection{Research design}

Questionnaires run as the main data while literature reviews run as minor data. The random sample for this research will be any houses in Iskandar Malaysia selected randomly by accessibility. Two jurisdictions of local authority in Iskandar Malaysia will be involved in this study which is Majlis Bandaraya Johor Bahru (Johor Bahru City Council) and Majlis Perbandaran Johor Bahru Tengah (Johor Bahru Tengah Municipal Council). For this research there will be a total of about 500 respondents for the two jurisdictions of local authority.

\subsection{Analysis mechanism}

The analysis mechanism used for data collection is a questionnaire. It will be deliberate as accurate as possible for respondents to be able to answer the question without difficulty. The study was steered using structured questionnaire that covered two basic principles which is about the waste management and the recycling knowledge. In this research, the questionnaire will be distributed to the respondent involved by hand. The final data were statistically analysed using the SPSS.

\section{Results and discussion}

4.1 Evaluation of Solid Waste Management in Majlis Bandaraya Johor Bahru (Johor Bahru City Council) and Majlis Perbandaran Johor Bahru Tengah (Johor Bahru Tengah Municipal Council)

Table 1: Results questionnaire for Waste Management

\begin{tabular}{|c|c|c|c|c|}
\hline & \multirow[t]{2}{*}{ Question } & \multirow[t]{2}{*}{ Answer } & \multicolumn{2}{|c|}{$\begin{array}{c}\text { Number of } \\
\text { Respondents }\end{array}$} \\
\hline & & & МРJB & MPJBT \\
\hline \multirow{3}{*}{ A1 } & \multirow{3}{*}{$\begin{array}{l}\text { The fulfilment } \\
\text { of the respondent } \\
\text { with the waste } \\
\text { collection system } \\
\text { in the area. }\end{array}$} & Yes & 148 & 171 \\
\hline & & No & 77 & 39 \\
\hline & & $\begin{array}{l}\text { Not } \\
\text { sure }\end{array}$ & 22 & 41 \\
\hline \multirow{3}{*}{$\mathrm{A} 2$} & \multirow{3}{*}{$\begin{array}{l}\text { The efficiency of } \\
\text { the collection } \\
\text { system. }\end{array}$} & Yes & 118 & 146 \\
\hline & & No & 68 & 54 \\
\hline & & $\begin{array}{l}\text { Not } \\
\text { sure }\end{array}$ & 60 & 50 \\
\hline
\end{tabular}




\begin{tabular}{|c|c|c|c|c|}
\hline \multirow[t]{3}{*}{ A3 } & $\begin{array}{l}\text { Frequent in a } \\
\text { week the trash }\end{array}$ & $\begin{array}{c}0-2 \\
\text { times }\end{array}$ & 154 & 180 \\
\hline & overflowed. & $\begin{array}{c}3-5 \\
\text { times }\end{array}$ & 85 & 65 \\
\hline & & $\begin{array}{c}5-7 \\
\text { times }\end{array}$ & 6 & 5 \\
\hline \multirow{3}{*}{ A4 } & Is odour, waste & Rarely & 88 & 113 \\
\hline & & Average & 122 & 111 \\
\hline & $\begin{array}{l}\text { are common in } \\
\text { your area? }\end{array}$ & Often & 37 & 27 \\
\hline \multirow{3}{*}{ A5 } & \multirow{3}{*}{$\begin{array}{l}\text { Amount of waste } \\
\text { generate each } \\
\text { day. }\end{array}$} & $\begin{array}{c}<0.6 \\
\mathrm{~kg} / \text { day }\end{array}$ & 78 & 90 \\
\hline & & $\begin{array}{c}0.6 \\
\mathrm{~kg} / \mathrm{day}\end{array}$ & 90 & 94 \\
\hline & & $\begin{array}{l}>0.6 \\
\mathrm{~kg} / \text { day }\end{array}$ & 74 & 65 \\
\hline
\end{tabular}

Question A1 was to classify the fulfillment of waste collection systems in the area and the outcomes shows that $59.9 \%$ of the residents were pleased with the collection system in MPJB while $68.1 \%$ were pleased in MPJBT. The number of residents were not pleased with the current method of waste collection were $31.2 \%$ for MPJB and $15.5 \%$ for MPJBT.

For question A2, 48\% of the residents in MPJB thought positively of the current collection system while $58.4 \%$ thought positively in MPJBT. $27.6 \%$ for MPJB and $21.6 \%$ for MPJBT did not consider the collection system is effective.

Results for question A3 displayed the residents opinions on the excess of trash bins 0-2 times a week were $62.9 \%$ for MPJB and 73\% for MPJBT, 3-5 times per week were $34.7 \%$ for MPJB and $26 \%$ for MPJBT and 5-7 timed per week were $2.4 \%$ for MPJB and $2 \%$ for MPJBT.

Furthermore, the results for question A4 showed $35.6 \%$ for MBJB and $45 \%$ for MPJBT of the residents thought of trash contamination in their area as exceptional, followed by $15 \%$ for MPJB and $10.8 \%$ for MBJBT showed contamination rate at trash house are often.

Results indicate that in question A5 32.2\% for MPJB and $36.1 \%$ for MPJBT residents expected waste generation amount is less than $0.6 \mathrm{~kg} /$ day while $30.6 \%$ for MPJB and $26.1 \%$ for MPJBT of residents will generate more than $0.6 \mathrm{~kg} /$ days.

\subsection{Awareness and Recycling knowledge of respondent}

Table 2 : Results questionnaire for Recycling Knowledge

\begin{tabular}{l|cccc}
\hline & Question & Answer & $\begin{array}{c}\text { Number of } \\
\text { Respondents }\end{array}$ \\
\cline { 2 - 5 } & & MPJB & MPJBT \\
\hline B1 & Knowledge & Yes & 162 & 164
\end{tabular}

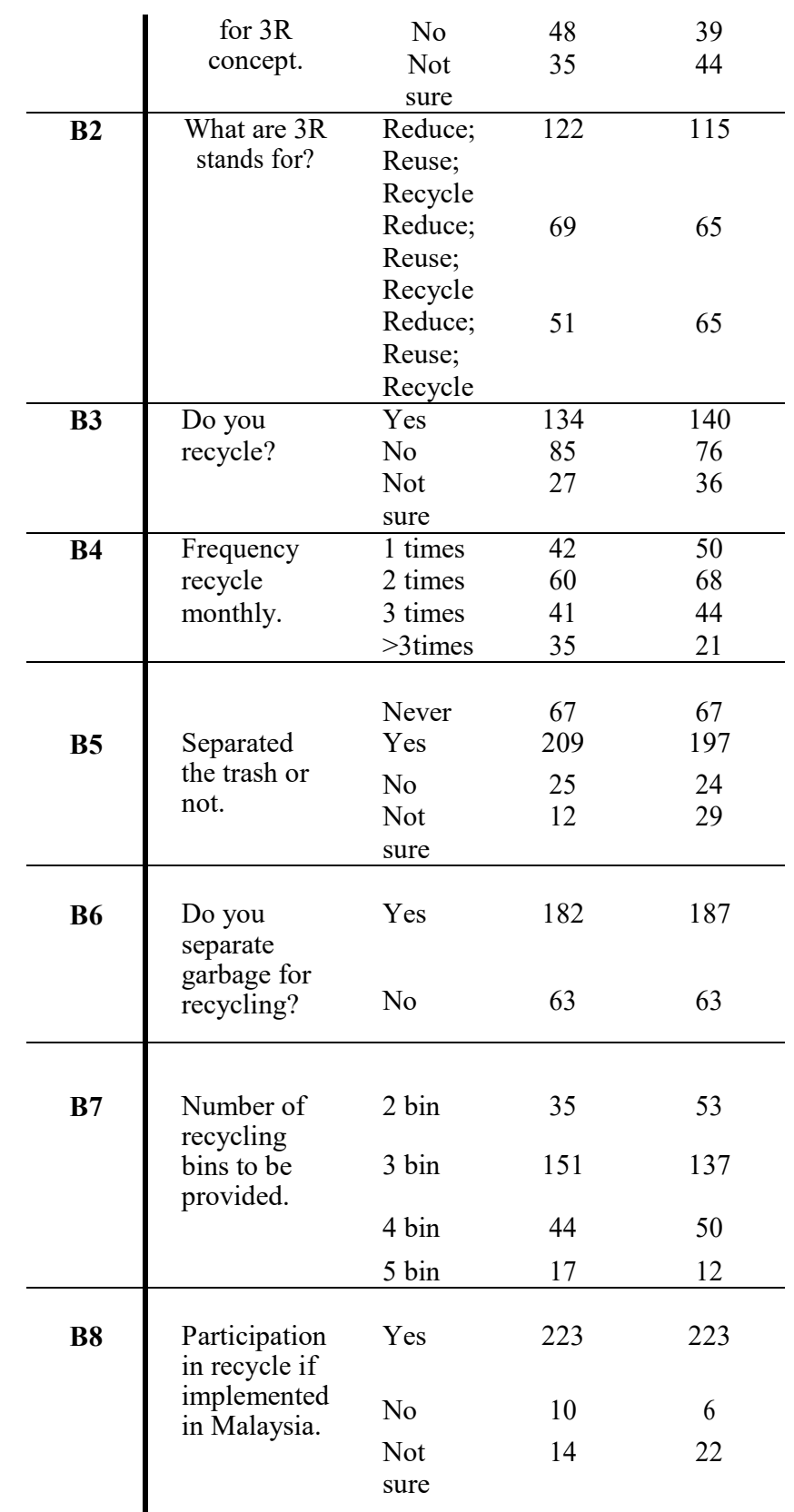

Results for question B1 showed a total of $66.1 \%$ for MBJB and $66.4 \%$ for MPJBT residents understood the concept of 3R. Meanwhile $19.6 \%$ for MPJB and $15.8 \%$ for MPJBT residents did not know about 3R concept.

For question B2, 50.4\% for MBJB and $46.9 \%$ for MPJBT residents knew the right order of 3R. Result for question B3 showed that $54.5 \%$ for MBJB and $55.5 \%$ for MPJBT residents carry out the recycling while $34.6 \%$ for MBJB and $30.2 \%$ for MPJBT residents did not perform recycling activities.

Results for question B4 showed that a sum of $17.1 \%$ residents in MBJB performed at least 1 time the recycling activities each month followed by $24.5 \%$ who had 2 times recycling per month, $16.7 \%$ residents ran 3 times per month, $14.3 \%$ residents in MBJB exceeded three times and $27.4 \%$ did not carried out any recycling activities. For residents in MPJBT, 20\% carried out at least 1 time, $27.2 \%$ carried out two times per month, $17.6 \%$ carried out three times per month, $8.4 \%$ 
exceeded three times per month and $26.8 \%$ of residents in MPJBT did not recycle at all.

Furthermore, question B5 indicate that $85 \%$ for MBJB and $78.8 \%$ for MPJBT residents will separate waste at source while $10.2 \%$ for MBJB and $9.6 \%$ for MPJBT residents will not separate the waste at source. Question B6 showed 74.3\% for MBJB and $74.8 \%$ for MPJBT will separate waste at source with the facilities available while $25.7 \%$ for MBJB and $25.2 \%$ for MPJBT residents thought not to separate the waste at source.

Result B7 showed that both residents in MBJB and MPJBT had a higher percentage of suggested the providing of 3 bins recycle bins which were $61.1 \%$ and $54.8 \%$ respectively. It is due to the people in Malaysia has been aware with the concept of 3 recycling bins. Question B8 showed a positive response of $90.3 \%$ for MBJB and $89.2 \%$ for MPJBT residents will discrete waste if recycling facilities are applied such as 2-bins or 3-bins recycle bins.

Results for question B1 showed a total of $66.1 \%$ for MBJB and $66.4 \%$ for MPJBT residents understood the concept of 3R. Meanwhile 19.6\% for MPJB and $15.8 \%$ for MPJBT residents did not know about 3R concept. For question B2, $50.4 \%$ for MBJB and $46.9 \%$ for MPJBT residents knew the right order of 3R. Result for question B3 showed that $54.5 \%$ for MBJB and $55.5 \%$ for MPJBT residents carry out the recycling while $34.6 \%$ for MBJB and $30.2 \%$ for MPJBT residents did not perform recycling activities.

Results for question B4 showed that a sum of $17.1 \%$ residents in MBJB performed at least 1 time the recycling activities each month followed by $24.5 \%$ who had 2 times recycling per month, $16.7 \%$ residents ran 3 times per month, $14.3 \%$ residents in MBJB exceeded three times and $27.4 \%$ did not carried out any recycling activities. For residents in MPJBT, 20\% carried out at least 1 time,27.2\% carried out two times per month, $17.6 \%$ carried out three times per month, $8.4 \%$ exceeded three times per month and $26.8 \%$ of residents in MPJBT did not recycle at all.

Furthermore, question $\mathrm{B} 5$ indicate that $85 \%$ for MBJB and $78.8 \%$ for MPJBT residents will separate waste at source while $10.2 \%$ for MBJB and $9.6 \%$ for MPJBT residents will not separate the waste at source. Question B6 showed $74.3 \%$ for MBJB and $74.8 \%$ for MPJBT will separate waste at source with the facilities available while $25.7 \%$ for MBJB and $25.2 \%$ for MPJBT residents thought not to separate the waste at source.

Result B7 showed that both residents in MBJB and MPJBT had a higher percentage of suggested the providing of 3 bins recycle bins which were $61.1 \%$ and $54.8 \%$ respectively. It is due to the people in Malaysia has been aware with the concept of 3 recycling bins. Question B8 showed a positive response of $90.3 \%$ for MBJB and $89.2 \%$ for MPJBT residents will discrete waste if recycling facilities are applied such as 2-bins or 3-bins recycle bins.

\section{Conclusion}

Due to the growth in population and economic development, reducing and recycling household waste has become progressively vital because waste generation has been increasing [6]. The balance of landfill areas is deteriorated and that makes recycling not only sensible but essential. Currently the waste disposal practice is that the household are required to place their waste in the bins that usually located in front of their houses and the collectors will gather the wastes twice a week. However, not all waste is disposed in such way.

From this study, most of the respondents have the knowledge of recycle, know the advantages of recycling and aware about the purpose of recycling but amazingly only few of the respondent practice recycle frequently. The reasons of most of the respondents is that there were not enough facility for waste separation and some of them stated that they were busy and did not have time to practice recycling.

There are many effective ways to promote recycle among household and one of the most operative way is television. Television can disseminate information to people with regards to recycle campaign. Nevertheless, the neighborhood themselves which is family and friends can deliver about recycling because people who practicing it frequently stated that they are the most influence in recycling resource. Since the respondents also cited that lack of facilities is one of the main reasons for not practicing recycle, the authority should provide more recycling facilities

The funding provided by the Ministry of Higher Education (MOHE) Malaysia and the management of Universiti Teknologi Mara (UiTM) Malaysia under the RAGS research grant scheme (600-RMI/RAGS 5/3 (178/2014)) are thanked

\section{Reference}

1. R. Othman, M. Yuhaniz, Centre of Environment Behaviour Studies, Faculty of Architecture, Planning and Surveying, UiTM Malaysia (2013)

2. S. Chandravathani,. Waste Reduction : No longer An option But a Necessity,Bernama.com, Bernama.com database, Institute of Biologocal Sciences: Kuala Lumpur (2008)

3. J. Othman, Household preferences for Solid Waste Management in Malaysia (2009)

4. A.V. Shekdar, Sustainable solid waste management : An integrated approach for Asian Countries, Waste Mangement 29(4), 1438-1448 (2009)

5. IRDA, Integrated Solid Waste Management Blueprint For Iskandar Malaysia (2011)

6. M. Akil, F. Johar, H. C. Siong, Household participation in recycling programs : A case study from Malaysia,Tata Loka Vol. 17, No. 2 (2015) 